UDC $577.32 ; 547.75 ; 544.18 ; 543.422 ; 66.095 .252 .091 .7$

\author{
B.F. Minaev, V.A. Minaeva, O.O. Panchenko, S.V. Bondarchuk
}

\title{
THE LOW-LYING TRIPLET EXCITED STATE OF N-SULFINYLANILINES EXPLAINS THEIR REACTIVITY AND INCLINATION TO CYCLOADDITION ACROSS $\mathrm{N}-\mathrm{S}=\mathrm{O}$ GROUP
}

\begin{abstract}
The Bohdan Khmelnytsky National University of Cherkasy, Cherkasy, Ukraine
Density functional theory calculations for $p$ - Br-N-sulfinylaniline and $m$-nitro-Nsulfinylaniline in the ground singlet $\left(\mathrm{S}_{0}\right)$ and triplet $\left(\mathrm{T}_{1}\right)$ excited states are presented and analyzed in terms of their specific physicochemical properties. As all aromatic Nsulfinylamines, these compounds are rather unstable being sensitive to moist air and we assign this instability to the thermally allowed $\mathrm{S}_{0} \rightarrow \mathrm{T}_{1}$ excitation induced by internal magnetic forces. Our calculations indicate that the $T_{1}-S_{0}$ energy gap in these molecules is unexpectedly low and spin-orbit coupling matrix element between these states is relatively high, being allowed by the orbital symmetry selection rules. We also apply the exchange mechanism of spin-catalysis concept in order to explain the prone of $\mathrm{N}$-sulfinylamines to the DielsAlder cycloaddition with dienes.
\end{abstract}

Keywords: spin-catalysis, cycloaddition, sulfinylamines, DFT, singlet-triplet energy gap.

DOI: $10.32434 / 0321-4095-2020-133-6-106-114$

\section{Introduction}

Aromatic sulfinylamines are relatively unstable and highly reactive compounds [1,2]; their functional moiety $\mathrm{Ar}-\mathrm{N}-\mathrm{S}=\mathrm{O}$ is prone to cycloaddition across the $\mathrm{N}-\mathrm{S}=\mathrm{O}$ group. Aromatic sulfinylamines participate in the Diels-Alder cycloaddition being active as a dienophile [1], or as 1,3-dipolar cycloaddition partner with arylnitril oxides and acrylonitryls [2]. These cycloaddition reactions provide an efficient route to useful drugs of the cyclic sulfonamides family [2]. The Diels-Alder reaction is one of the most understood and widely used in modern organic synthesis. In particular, this is achieved due to its unmatched ability to rapidly generate complex molecular structures with the simultaneous formation of two carbon-carbon bonds. This is confirmed by the considerable number of publications on the subject. The study of dienophiles is important from a historical point of view as they, together with quinones, were the first substances to be studied by Diels and Alder, the results of which then laid down the canons of organic synthesis reactions. As far as we know, the high reactivity of sulfinylamines and their trend to cycloaddition (Scheme 1) have not been reliably explained in terms of their electronic structure and thermokinetics. Here we are going to explain these chemical reactive properties on the ground of quantum chemical calculations with account of spin effects and internal magnetic perturbation.

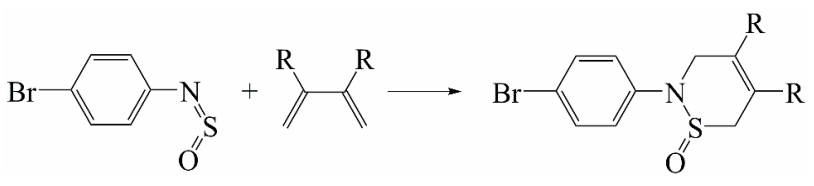

Scheme 1. Example of cycloaddition reaction for $p-\mathrm{Br}-\mathrm{N}-$ sulfinylaniline and diene

\section{Experimental}

In the present work, we have explained the high reactivity of aryl sulfinylamines in respect to Diels-Alder cycloaddition in qualitative terms of spincatalysis theory [3,4] applying density functional theory (DFT) calculations [5] of the singlet and triplet states of the $p$-Br-phenyl and nitro derivatives. Both $\mathrm{S}_{0}$ and $\mathrm{T}_{1}$ structures of $p$-Br-N-sulfinylaniline are shown in Fig. 1, being optimized by DFT method with the B3LYP functional and $6-31 \mathrm{G}^{*}$ basis set [5]. The triplet state was calculated by using the spinunrestricted B3LYP functional and the Hartree-Fock self-consistent field method in PM3 approximation [6]. Geometry optimization was supported by the force-field and vibrational normal modes calculations. All calculated IR frequencies of both states are real,

(C) B.F. Minaev, V.A. Minaeva, O.O. Panchenko, S.V. Bondarchuk, 2020

B.F. Minaev, V.A. Minaeva, O.O. Panchenko, S.V. Bondarchuk 
which indicates the true energy minimum location. One can see that the $\mathrm{N}=\mathrm{S}$ bond $(1.55 \AA)$ of the singlet ground state is prolonged being excited in the triplet $\left(\mathrm{T}_{1}\right)$ excited state up to $1.72 \AA$. The most important for our purposes is the fact that the $\mathrm{N}-\mathrm{S}=\mathrm{O}$ moiety in the $\mathrm{T}_{1}$ state is out-of-plane distorted; this obstacle will be crucial for spin-orbit coupling calculation and for relatively low thermokinetic stability of N-sulfinylamines.

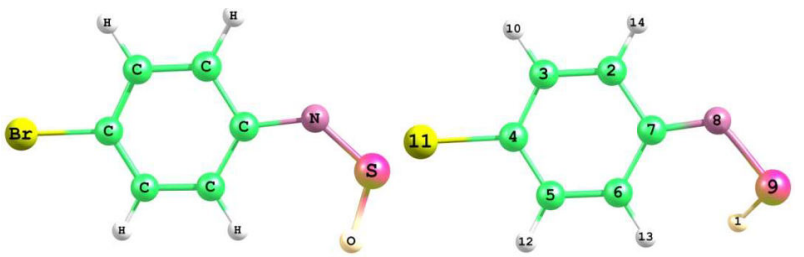

Fig. 1. The structure of the singlet (left) and triplet states (right) of $p$-Br-N-sulfinylaniline optimized by DFT/B3LYP method and the atomic numbering

All calculations in this work correspond to vacuum condition and are performed with the Gaussian09 code [5].

\section{Results and discussion}

The $c i s$-form of studied $p$ - $\mathrm{Br}-\mathrm{N}$-sulfinylaniline is more stable than the trans-configuration by $20.1 \mathrm{~kJ} \mathrm{~mol}^{-1}$ as follows from B3LYP optimization in the ground singlet state and the rotation barrier is equal to $34.3 \mathrm{~kJ} \mathrm{~mol}^{-1}$. Thus, in the following we consider only cis-configuration for all compounds. We have to discuss first the comparison of electronic structures in the $\mathrm{S}_{0}$ and $\mathrm{T}_{1}$ states of $p-\mathrm{Br}-\mathrm{N}$ sulfinylaniline obtained by DFT method. The Mulliken atomic charges obtained by DFT method for both states are shown in Table 1; they are rather similar, but a bit higher electric polarization of the $\mathrm{N}=\mathrm{S}=\mathrm{O}$ group in the ground singlet state can be stressed in comparison with the triplet state. At the same time, the $T_{1}$ state has a larger dipole moment $(3.21 \mathrm{D})$ than the singlet state $(1.48 \mathrm{D})$ because of non-planar structure of the former and its additional $s p$ hybridization contribution. The Mulliken atomic spin densities for the triplet state are also given in Table 1. The spin density is almost localized on the NSO group with small penetration to the ortho- and para-positions of the phenyl ring (Table 1); metha atoms (3 and 5) bear small negative spin density as well as a-carbon. As we shall see this particular spin polarization of the $T_{1}$ state is essential for the Diels-Alder cycloaddition in terms of spin-catalysis theory [6].

The high electric polarization of the $\mathrm{N}-\mathrm{S}=\mathrm{O}$ group in the both states can be explained by a strong charges alternation on the $\mathrm{N}, \mathrm{S}$ and $\mathrm{O}$ atoms $(\stackrel{\delta-}{\mathrm{N}}-\stackrel{\delta+}{\mathrm{S}}=\stackrel{\delta-}{\mathrm{O}})$, where $\delta$ being about $0.5-0.7$ in the singlet ground state and approximately equal in the triplet state $\delta=0.5-0.6$. These results are important

Table 1

Mulliken atomic spin densities and Mulliken atomic charges of $\mathrm{N}$-sulfinylanilines

\begin{tabular}{|c|c|c|c|c|c|c|c|}
\hline Molecule & \multicolumn{4}{|c|}{$p$-Br-N-sulfinylaniline } & \multicolumn{3}{|c|}{$m$-nitro-N-sulfinylaniline } \\
\hline \multirow[b]{2}{*}{ Atom } & Singlet & \multicolumn{3}{|c|}{ Triplet } & \multirow{2}{*}{\begin{tabular}{|c|} 
Singlet \\
Mulliken \\
atomic charges
\end{tabular}} & \multicolumn{2}{|c|}{ Triplet } \\
\hline & $\begin{array}{l}\text { Mulliken } \\
\text { atomic } \\
\text { charges }\end{array}$ & $\begin{array}{l}\text { Mulliken } \\
\text { atomic } \\
\text { charges }\end{array}$ & $\begin{array}{l}\text { Mulliken } \\
\text { atomic spin } \\
\text { densities }\end{array}$ & $\begin{array}{l}\text { UHF PM3 } \\
\text { spin density }\end{array}$ & & $\begin{array}{c}\text { Mulliken } \\
\text { atomic charges }\end{array}$ & $\begin{array}{l}\text { Mulliken } \\
\text { atomic spin } \\
\text { densities }\end{array}$ \\
\hline $1 \mathrm{O}$ & -0.512 & -0.490 & 0.474 & 0.484 & -0.466 & -0.476 & 0.486 \\
\hline $2 \mathrm{C}$ & -0.118 & -0.110 & 0.253 & 0.617 & -0.101 & -0.174 & 0.291 \\
\hline $3 \mathrm{C}$ & -0.156 & -0.149 & -0.138 & -0.504 & -0.140 & 0.267 & -0.136 \\
\hline $4 \mathrm{C}$ & 0.093 & 0.089 & 0.314 & 0.602 & -0.149 & -0.136 & 0.313 \\
\hline $5 \mathrm{C}$ & -0.162 & -0.156 & -0.139 & -0.502 & 0.271 & -0.143 & -0.143 \\
\hline $6 \mathrm{C}$ & -0.151 & -0.139 & 0.262 & 0.615 & -0.187 & -0.091 & 0.259 \\
\hline $7 \mathrm{C}$ & 0.241 & 0.284 & -0.100 & -0.400 & 0.253 & 0.277 & -0.125 \\
\hline $8 \mathrm{~N}$ & -0.525 & -0.562 & 0.550 & 0.597 & -0.545 & -0.550 & 0.600 \\
\hline $9 \mathrm{~S}$ & 0.702 & 0.608 & 0.500 & 0.541 & 0.735 & 0.626 & 0.496 \\
\hline $10 \mathrm{H}$ & 0.164 & 0.170 & 0.005 & 0.034 & 0.163 & 0.167 & 0.005 \\
\hline $11 \mathrm{Br}$ & -0.107 & -0.080 & 0.040 & -0.033 & & & \\
\hline $11 \mathrm{H}$ & & & & & 0.189 & 0.200 & -0.014 \\
\hline $12 \mathrm{H}$ & 0.167 & 0.173 & 0.005 & 0.034 & & & \\
\hline $12 \mathrm{~N}$ & & & & & 0.381 & 0.392 & 0.008 \\
\hline $13 \mathrm{H}$ & 0.202 & 0.191 & -0.015 & -0.042 & 0.189 & 0.226 & -0.015 \\
\hline $14 \mathrm{H}$ & 0.163 & 0.171 & -0.011 & -0.042 & 0.177 & 0.176 & -0.011 \\
\hline $15 \mathrm{O}$ & & & & & -0.386 & -0.377 & -0.014 \\
\hline $16 \mathrm{O}$ & & & & & -0.383 & -0.385 & -0.001 \\
\hline
\end{tabular}


for explanation of 1,3-dipolar cycloaddition in respect to arylnitril oxides [2]. The $\mathrm{Br}$ atom makes a little contribution to electric polarization and provides a small negative charge of about -0.1 .

The ground singlet state of $p-\mathrm{Br}-\mathrm{N}-$ sulfinylaniline has the total energy -3330.86823 a.u. and the $T_{1}$ state energy is equal to -3330.81699 a.u. as optimized with the B3LYP functional. Thus, the $\mathrm{S}-\mathrm{T}$ energy gap is only 0.05124 a.u. $(1.39 \mathrm{eV})$, which corresponds to the $0-0$ transition wavelength of phosphorescence $885 \mathrm{~nm}$. This is unusually low $\mathrm{S}-\mathrm{T}$ energy gap for aromatic compound with one phenyl ring. For benzene and brombenzene molecules, this gap is close to $3.7 \mathrm{eV} \mathrm{[7-9].} \mathrm{The} \mathrm{low-lying} \mathrm{triplet}$ excited state of this $p$-Br-sulfinylamine correlates well with its high chemical reactivity in respect to DielsAlder cycloaddition with dienes, dienophiles and 1,3-dipolarophiles $[1,2]$ accounting the high spin density at the NSO group and the large dipole moment (Table 1).

Comparison with other condensed aromatic hydrocarbons consisting of larger number of cycles is important in this respect. Naphthalene, anthracene, tetracene and pentacene molecules have the following $\mathrm{T}_{1}$ state energies decreasing in the row: 2.6, 1.7, 1.3 and $0.9 \mathrm{eV}$ [8-11]. Aromatic hydrocarbons with three and larger number of cycles easy enter the diene synthesis and starting with tetracene their stability is going down fast [11]. Aromaticity of these compounds also falls down which rises their chemical activity; even anthracene $(1.7 \mathrm{eV})$ is prone to produce dimerization and the Diels-Alder reactions. These trends can be explained in terms of exchange spincatalysis $[3,4,10]$; according to this concept, just the triplet excited state determines such chemical reactivity.

Accounting importance of triplet state, we have compared the S-T energy gap not only with B3LYP density functional but also with five others DFT methods. All calculations are collected in Table 2. The B3LYP, PBE0, CAM-B3LYP functional provide small values of $\mathrm{S}-\mathrm{T}$ energy gap: from 1.33 to $1.41 \mathrm{eV}$. In contrast, BMK, M06, M06-2X gives us something larger values of 1.50 to $1.54 \mathrm{eV}$. However, all these results agree with qualitative abnormally low-lying triplet excited state for such aromatic compound. This is also should be noted that the $\mathrm{S}-\mathrm{T}$ gap for analyzed compound is much lower than, for example, for benzene molecule $(3.66 \mathrm{eV})$ [11], which is relative to the studied species.

We have also compared geometric parameters, such as bond lengths and angles that belong to the NSO group calculated in the singlet and triplet state, by two different methods: DFT and PM3 [9] (Table 3). The triplet state has a non-planar structure in ${ }^{3}$ DFT calculation (Fig. 1). This out-of-plane bending concerns mainly the $\mathrm{N}-\mathrm{S}=\mathrm{O}$ group. Such geometry deformation upon $\mathrm{S}-\mathrm{T}$ excitation is very important for internal magnetic perturbation responsible for the spin-forbidden $\mathrm{S}-\mathrm{T}$ transformation which will be discussed latter. We shall see that the out-of-plane bending in the $\mathrm{N}-\mathrm{S}=\mathrm{O}$ group will lead to a non-zero matrix element of the spinorbit coupling (SOC) operator because of large SOC contributions from the $\mathrm{N}, \mathrm{S}$ and $\mathrm{O}$ atoms at the intersection of singlet and triplet states. The PM3 method provides the plane structure of all studied sulfinylaniline molecules in both $\mathrm{S}_{0}$ and $\mathrm{T}_{1}$ states. These calculations have been performed first from the beginning of the project and they provided such low triplet state energy that the S-T energy gap become negative. The PM3 prediction of paramagnetic character for all studied N-sulfinylaniline molecules compels us to pay more attention to the problem and to apply more accurate DFT methods.

We have to stress that out B3LYP/6-31G* results for the $p-\mathrm{Br}-\mathrm{N}$-sulfinylaniline molecule are qualitatively similar to those for the nitro-derivative (Tables 2 and 3). The S-T energy gap is equal to $1.13 \mathrm{eV}$ in the latter case. The main difference concerns the dihedral angle $\mathrm{SNC}^{7} \mathrm{C}^{2}$ for the nitro compound, which corresponds to a larger out-ofplane deviation in the $\mathrm{S}_{0}$ state in comparison with the Br-derivative. This dihedral angle does not influence much the results of spin-orbit coupling calculations, while the $\mathrm{OSNC}^{7}$ is practically the same for both $\mathrm{N}$-sulfinylaniline molecules, which really matters for magnetic perturbation.

Thus, the spin-unrestricted DFT calculation of the optimized triplet state provides much more accurate $T_{1}$ structure with large out-of-plane deformation, though the semi-empirical PM3 method is less sensitive for the force field change

Table 2

$\mathrm{S}-\mathrm{T}$ energy gap values calculated in different DFT-functionals for $\boldsymbol{p}$ - $\mathrm{Br}-\mathrm{N}$-sulfinylaniline

\begin{tabular}{c|c|c|c|c|c|c}
\hline Functional & B3LYP & BMK & PBE0 & M06 & M06-2X & CAM-B3LYP \\
\hline${ }^{3}$ E, a. u. & -3330.81699 & -3329.16263 & -3329.92496 & -3330.38197 & -3330.69529 & -3330.72250 \\
\hline${ }^{1}$ E, a. u. & -3330.86823 & -3329.21931 & -3329.97675 & -3330.43850 & -3330.75027 & -3330.77133 \\
\hline$\Delta \mathrm{E}, \mathrm{eV}$ & 1.39 & 1.54 & 1.41 & 1.54 & 1.50 & 1.33 \\
\hline
\end{tabular}


Geometry parameters of $\mathrm{N}$-sulfinylaniline calculated with different functionals

\begin{tabular}{c|c|c|c|c|c|c|c}
\hline Molecule & \multicolumn{4}{|c|}{$p$-Br-N-sulfinylaniline } & \multicolumn{2}{c}{$m$-nitro-N-sulfinylaniline } \\
\hline Bond, angle & Experiment $\mathrm{S}_{0}[2]$ & ${ }^{1} \mathrm{PM} 3$ & ${ }^{3} \mathrm{PM} 3$ & ${ }^{1} \mathrm{DFT}$ & ${ }^{3} \mathrm{DFT}$ & ${ }^{1} \mathrm{DFT}$ & ${ }^{3} \mathrm{DFT}$ \\
\hline $\mathrm{S}-\mathrm{O}$ & 1.467 & 1.491 & 1.530 & 1.494 & 1.527 & 1.477 & 1.525 \\
\hline $\mathrm{S}-\mathrm{N}$ & 1.513 & 1.590 & 1.727 & 1.549 & 1.720 & 1.558 & 1.728 \\
\hline $\mathrm{N}-\mathrm{C}^{7}$ & 1.397 & 1.406 & 1.322 & 1.392 & 1.341 & 1.404 & 1.345 \\
\hline $\mathrm{OSN}$ & 120.5 & 111.4 & 106.5 & 120.0 & 111.3 & 112.9 & 110.3 \\
\hline $\mathrm{SNC}^{7}$ & 133.5 & 139.0 & 130.3 & 131.1 & 120.9 & 120.2 & 120.6 \\
\hline $\mathrm{OSNC}^{7}$ & 1.3 & 0 & 0 & 0.002 & 57.6 & 175.5 & -57.8 \\
\hline $\mathrm{SNC}^{7}$ & -1.2 & 0 & 0 & -0.016 & -4.7 & 146.4 & -177.5 \\
\hline
\end{tabular}

upon $\mathrm{S}-\mathrm{T}$ transition.

Exchange induced spin-catalysis and correlation diagram for cycloaddition reactions

There is also an important sequence of such $\mathrm{T}$ state peculiarity of the studied $\mathrm{N}$-sulfinylaniline compounds. According to spin-catalysis concept, the lower S-T energy gap corresponds to the lower activation barrier in concerted cycloaddition reaction [4]. Two triplet states of both reactants, N-sulfinylaniline $\left({ }^{3} \mathrm{~S}\right)$ and diene $\left({ }^{3} \mathrm{D}\right)$ form the doubly excited triplet state with zero spin of united reactant system $\left({ }^{1}\left(S^{3} \mathrm{D}\right)\right)$ which correlates directly with the ground singlet state $\left({ }^{1} \mathrm{P}_{0}\right)$ of the cycloaddition product (Fig. 2$)$. In Fig. 2, we apply another presentation of the triplet $\mathrm{T}_{1}$ state by using multiplicity notation $\left({ }^{3} \mathrm{~S}\right)$ in order to distinguish from diene reactant $\left({ }^{3} \mathrm{D}\right)$. The ground singlet state of both reactants $\left({ }^{1} \mathrm{~S}_{0}{ }^{1} \mathrm{D}_{0}\right)$ does not fit to the structure of the ground state product without spin decoupling; thus, it provides adiabatic correlation with the excited singlet state product $\left({ }^{1} \mathrm{P}^{*}\right)$. The lower energy of this doubly-excited triplet state ${ }^{1}\left({ }^{3} S^{3} D\right)$ with zero spin, the lower crossing point between it and the ground state of the reactants ${ }^{1}\left({ }^{1} \mathrm{~S}_{0}{ }^{1} \mathrm{D}_{0}\right)$; this crossing provides the activation barrier of the cycloaddition reaction (Fig. 2).

Since both states forming the crossing point possess the same spin multiplicity (both are singlet states), they need to avoid crossing by account of intermolecular exchange interaction (Scheme 2) [6].

This process can be represented by exchange integral of the type shown in equation (1), which occurs as configuration interaction (CI) matrix element with the ground reactant state ${ }^{1}\left({ }^{1} \mathrm{~S}_{0}{ }^{1} \mathrm{D}_{0}\right)$ being responsible for the energy splitting at the avoided crossing and for the rate of activation barrier overcoming $[3,4]$ :

$$
\begin{aligned}
& <\left(\mathrm{S}_{0} \mathrm{D}_{0}\right)\left|\mathrm{H}_{\mathrm{CI}}\right|^{1}\left({ }^{3} \mathrm{~S}^{3} \mathrm{D}\right)>= \\
& =\iint \mathrm{i}(1) \mathrm{u}(2) \frac{\mathrm{e}^{2}}{\mathrm{r}_{1,2}} \mathrm{j}(1) \mathrm{v}(2) \mathrm{dv}_{1} \mathrm{dv}_{2} .
\end{aligned}
$$

The avoiding crossing in Fig. 2 would have low energy since the triplet state of the $\mathrm{N}$-sulfinylaniline $\left({ }^{3} \mathrm{~S}\right)$ possesses the unusually small $\mathrm{S}-\mathrm{T}$ excitation gap. Thus, the low-lying triplet excited state of $\mathrm{N}$ sulfinylaniline $\left({ }^{3} \mathrm{~S}\right)$ provides the easy reaction with dien and relatively low activation barrier.

The studied N-sulfinylanilines (ArNSO) are strong dienophiles while the relative arylsocianate

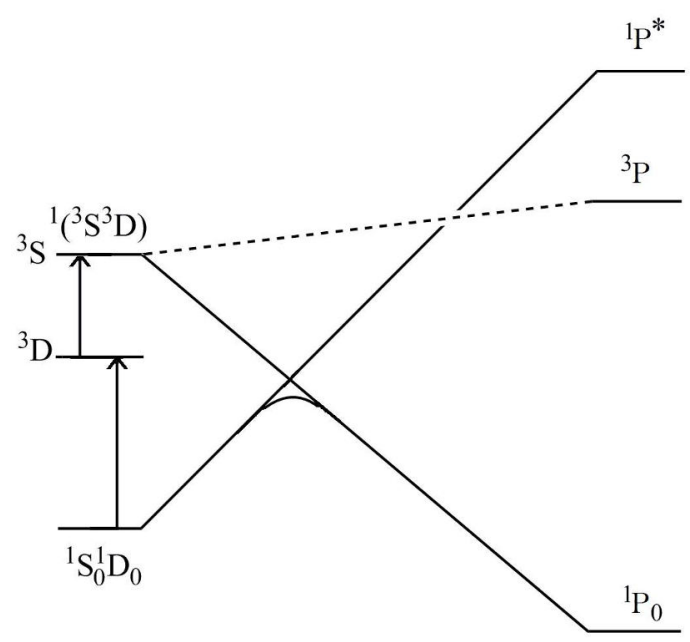

Fig. 2. Schematic presentation of states correlation diagram for potential energy curves along reaction path for concerted cycloaddition reaction between N-sulfinylaniline (S) and diene (D); the activation barrier of reaction is formed by avoiding crossing of two common singlet states (for the whole reacting system D+S). Symbol P means cycloaddition product

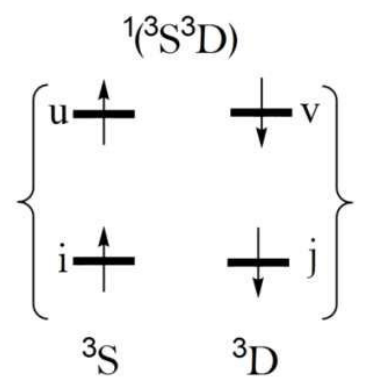

Scheme 2. The doubly-triplet common state configuration with the total zero spin 
(ArNCO) molecules are poor dienophiles [2]. Our B3LYP/6-31G* calculations show that the singlet ground state of phenyl-NCO lies by $263.3 \mathrm{~kJ} \mathrm{~mol}^{-1}$ lower than the triplet excited state optimized with UB3LYP method. The geometry of the calculated of ArNCO compound resembles a trans-form for both singlet and triplet states. This can be explained by the difference in a number of occupied MO in the molecular valence shell in comparison with ArNSO compound by two electrons. Thus, we see that HOMO in ArNSO becomes a free (vacant) orbital in the ArNCO entire p-system; its energy is $-0.98 \mathrm{eV}$. This observation reflects the qualitative character of the mentioned frontier orbitals and their bonding-antibonding peculiarities. It is well known that the Diels-Alder reaction can be explained by the interaction of the HOMO and LUMO-orbitals of diene and dienophile [3,4]. Indeed, the DFT calculations for the ground state of 4-bromo-Nsulfinylaniline yielded LUMO energy $(\varepsilon=-3.0 \mathrm{eV})$, which is very close to the well-known dienophiles of maleic anhydride (LUMO $\varepsilon=-3.2 \mathrm{eV}$ ), both being calculated according to $\mathrm{B} 3 \mathrm{LYP} / 6-31 \mathrm{G}^{*}$ method. These calculations support our spin-catalysis concept and explain why the arylsocianates are much poor dienophiles in comparison with $\mathrm{N}$-sulfinylanilines. stability

Analysis of the $N$-sulfinylaniline molecular

The N-sulfinylaniline molecule in the ground singlet state $\left({ }^{1} \mathrm{~S}_{0}\right)$ is planar. The PM3 method gives a planar structure for both singlet ${ }^{1} \mathrm{~S}_{0}$ and triplet $\left({ }^{3} \mathrm{~S}\right)$ states; the latter is of the ${ }^{3}\left(\pi \pi^{*}\right)$-type. In this case, the spin-orbit coupling (SOC) between the ${ }^{1} \mathrm{~S}_{0}$ and ${ }^{3} \mathrm{~S}$ states is equal to zero in the single-electron effective approximation [7], which is reliable and repeatedly verified for many molecules [9-15]. The out-of-plane distorted singlet and triplet states at the $\mathrm{S}-\mathrm{T}$ crossing point are capable of mixing due to the spin-orbit coupling operator, which can be represented in an effective one-electron form $[7,11]$ :

$$
\begin{aligned}
& \mathrm{H}_{\mathrm{SO}}=\sum_{\mathrm{A}} \zeta_{\mathrm{A}} \sum_{\mathrm{i}} \hat{\mathrm{l}}_{\mathrm{i}, \mathrm{A}} \cdot \hat{\mathrm{s}}_{\mathrm{i}}=\sum_{\mathrm{i}} \hat{\mathrm{B}}_{\mathrm{i}, \mathrm{A}} \cdot \hat{\mathrm{s}}_{\mathrm{i}}= \\
& =\sum_{\mathrm{i}}\left(\mathrm{B}_{\mathrm{i}}^{\mathrm{x}} \mathrm{s}_{\mathrm{i}}^{\mathrm{x}}+\mathrm{B}_{\mathrm{i}}^{\mathrm{y}} \mathrm{s}_{\mathrm{i}}^{\mathrm{y}}+\mathrm{B}_{\mathrm{i}}^{\mathrm{z}} \mathrm{s}_{\mathrm{i}}^{\mathrm{z}}\right),
\end{aligned}
$$

where $\zeta_{A}$ is the SOC constant for valence shell of atom $\mathrm{A}$, which determines the splitting of multiplets in the atomic spectrum; $\hat{l}_{\mathrm{i}, \mathrm{A}}$ and $\hat{\mathrm{s}}_{\mathrm{i}}$ are the operators of the orbital and spin angular moments of an i-th electron, respectively [7].

$$
\text { Symbol } B_{i}^{z}=\sum_{i} \zeta^{A} l_{i z}^{A} \text { denotes the orbital part }
$$
of the SOC operator with $z$-projection in the molecular Cartezian coordinate system [8].

Formula (2) was obtained by taking into account single-center contributions using atomic parameters $\zeta_{A}$ and neglecting all two-center terms; that is why we obtain the SOC calculation in a good approximation on the ground of an effective singleelectron Hamiltonian. It is important that it is necessary to neglect the differential overlap and use PM3 method when calculating the matrix elements of operator (2). This approximation is the more reliable the higher the difference between singlecenter SOC contributions for the molecule and $\zeta_{A}$ values. Changes in the valence shell of a molecule (hybridization and polarization) should not greatly affect the value of the $\zeta_{A}$ constant. After all, twoelectrons SOC contributions are determined mainly by interaction of internal and external electrons, as shown by the atomic calculations and these are taken into account by the semiempirical $\zeta_{A}$ constant. At the same time, two-center SOC integrals show trend to be cancelled for the single- and two-electron SOC contributions which have opposite signs and are comparable by the absolute values. Thus, the effective SOC operator (2) is a good approach for internal magnetic calculations in terms of PM3 wave functions presented in Scheme 3.

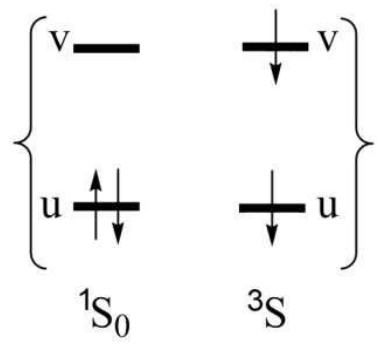

Scheme 3. Two configurations for SOC matrix element between the singlet ${ }^{1} \mathrm{~S}_{0}$ and triplet ${ }^{3} \mathrm{~S}$ states which involve the highest occupied molecular orbital (HOMO) $u$ and the lowest unoccupied molecular orbital (LUMO) $v$ inside the $\mathrm{N}$ sulfinylaniline molecule

As we can see from Scheme 3, two presented electrons have different occupations in the matrix element of the SOC operator (2) between the ground singlet $\left({ }^{1} \mathrm{~S}_{0}\right)$ and the triplet excited $\left({ }^{3} \mathrm{~S}\right)$ states; for the z-component of the scalar product (2) this SOC matrix element is equal to:

$\left\langle{ }^{1} \mathrm{~S}_{0}\left|\mathrm{H}_{\mathrm{SO}}^{\mathrm{z}}\right|{ }^{3} \mathrm{~T}_{\mathrm{u}-\mathrm{v}}^{\mathrm{z}}\right\rangle=-\sqrt{2} \mathrm{~B}_{\mathrm{uv}}^{\mathrm{z}}$,

where $u$ and $v$ are the HOMO and LUMO orbitals singly occupied in the lowest triplet state; $\mathrm{T}^{\mathrm{z}}$ means 
triplet state with zero spin projection on z-axis.

Thus, in the general case, for MOs that are constructed with the real AO $2 s, 2 p$-basis, we obtain one-electron orbital integrals with operator $B$ in the SOC Hamiltonian. The orbital parts of the matrix element of the SOC operator between the triplet and singlet states in Scheme 3 are equal to [7]:

$$
\begin{aligned}
& \mathrm{B}_{\mathrm{uv}}^{\mathrm{x}}=\frac{\mathrm{i}}{2} \sum_{\mathrm{A}}\left(\mathrm{c}_{\mathrm{yu}}^{\mathrm{A}} \mathrm{c}_{\mathrm{zv}}^{\mathrm{A}}-\mathrm{c}_{\mathrm{zu}}^{\mathrm{A}} \mathrm{c}_{\mathrm{yv}}^{\mathrm{A}}\right) \zeta_{\mathrm{A}}, \\
& \mathrm{B}_{\mathrm{uv}}^{\mathrm{y}}=\frac{\mathrm{i}}{2} \sum_{\mathrm{A}}\left(\mathrm{c}_{\mathrm{zu}}^{\mathrm{A}} \mathrm{c}_{\mathrm{xv}}^{\mathrm{A}}-\mathrm{c}_{\mathrm{xu}}^{\mathrm{A}} \mathrm{c}_{\mathrm{zv}}^{\mathrm{A}}\right) \zeta_{\mathrm{A}}, \\
& \mathrm{B}_{\mathrm{uv}}^{\mathrm{z}}=\frac{\mathrm{i}}{2} \sum_{\mathrm{A}}\left(\mathrm{c}_{\mathrm{xu}}^{\mathrm{A}} \mathrm{c}_{\mathrm{yv}}^{\mathrm{A}}-\mathrm{c}_{\mathrm{yu}}^{\mathrm{A}} \mathrm{c}_{\mathrm{xv}}^{\mathrm{A}}\right) \zeta_{\mathrm{A}} .
\end{aligned}
$$

where $\zeta_{\mathrm{A}}$ are the SOC constants of valence $2 p$ or $3 p$-shells of $\mathrm{C}, \mathrm{N}, \mathrm{S}, \mathrm{O}$ atoms; $\mathrm{A}$ is the number of an atom, $\mathrm{c}_{\mathrm{yu}}^{\mathrm{A}}$ is the expansion coefficient for $u$-th $\mathrm{MO}$ of the $2 \mathrm{p}_{y}-\mathrm{AO}$ at the atom $A$.

This is because the orbital angular momentum operator $1_{z}^{A}$ produces rotation of atomic $2 p_{x}, 2 p_{y}$ orbitals around $z$ axis inside A atom: $1_{z} \varphi_{\mathrm{py}}=-\mathrm{i} \hbar \varphi_{\mathrm{px}}$, where $i=\sqrt{-1}$. For the $B_{\text {uv }}^{\mathrm{x}}$ and $\mathrm{B}_{\mathrm{uv}}^{\mathrm{y}}$ integrals, we get the analogous equations [7]. The calculated summarized value of the square of the SOC matrix element for the $p-\mathrm{Br}-\mathrm{N}$-sulfinylaniline molecule is as follows:

$$
\begin{aligned}
& \left|\left\langle\mathrm{S}_{0}\left(\mathrm{H}_{\mathrm{SO}}\right) \mathrm{T}_{\mathrm{u}-\mathrm{v}}\right\rangle\right|^{2}= \\
& =\left|\left\langle\left(\mathrm{H}_{\mathrm{SO}}^{\mathrm{x}}\right)\right\rangle\right|^{2}+\left|\left\langle\left(\mathrm{H}_{\mathrm{SO}}^{\mathrm{y}}\right)\right\rangle\right|^{2}+\left|\left\langle\left(\mathrm{H}_{\mathrm{SO}}^{\mathrm{x}}\right)\right\rangle\right|^{2}= \\
& =2.954+87.236+80.82=171.01\left(\mathrm{~cm}^{-1}\right) .
\end{aligned}
$$

This calculation is performed in terms of selfconsistent field theory (PM3) at the triplet state geometry optimized by DFT method, which is close to the $\mathrm{S}-\mathrm{T}$ crossing point. The biggest contribution to the SOC integral is produced by $\mathrm{N}, \mathrm{O}$ and $\mathrm{S}$ atoms. The $\mathrm{C}$ and $\mathrm{Br}$ atoms provide very small $\mathrm{SOC}$ contributions in all three directions. The optimal geometry of the ${ }^{3} \mathrm{~S}$ state in the DFT method, as already mentioned, gives a non-planar structure and a relatively large contribution to the SOC matrix element. The similar result is obtained for $m$-nitro$\mathrm{N}$-sulfinylaniline $\left(173.5 \mathrm{~cm}^{-1}\right)$. Therefore, we can say that the $\mathrm{N}-\mathrm{S}=\mathrm{O}$ group of atoms which emerges the out-of-plane distortion upon $\mathrm{S}-\mathrm{T}$ transition and deviates from the planar structure leads to a large mixing of the $\pi$ and $\sigma$-orbitals and finally to effective
SOC matrix element. In terms of Landau-Zener approximation, the value (5) determines the rate constant of the spin flip transition [11]. Thus, when a deformation vibration of the $\mathrm{N}-\mathrm{S}=\mathrm{O}$ group is heated or easily excited upon spin flip, the singlettriplet transition in this molecule is possible. That is why the $\mathrm{N}$-sulfinylanilines are prone to spin decoupling being rather unstable species with a restricted lifetime in the moist air [1,2]. Triplet state reactions with the triplet ground state oxygen are not forbidden by spin selection rules [12-15] and such organic species can be easily oxidized [13]. This is one of the possible reasons of their common chemical instability in the presence of oxygen and water vapor [12-15].

Comparison of DFT and PM3 methods is important and deserves additional discussion. Spin unrestricted DFT method for the triplet state (Table 1) provides close results to PM3 approach in the unrestricted Hartree-Fock (UHF) frame as it concerns the spin density distribution. In the triplet state, the structure of the electronic shell is close to canonical form (Fig. 3,b), which corresponds to a sulfide type of sulfur. Spin density distribution of the triplet state calculated by DFT method (Table 1) differs from PM3 result mostly for the benzene ring moiety. Spin density on carbon atoms of the ring shows strong spin polarization in PM3 method, which is typical and well-known overestimation of the UHF PM3 approach [5,9]. However, DFT and PM3 methods provide similar values for other atoms (Table 1). Excess of spin polarization in PM3 calculation diminishes the reliability of the UHF approach; this leads to low energy predication for the triplet state. The UHF PM3 method predicts the triplet state with the lower heat of formation $\left(125.86 \mathrm{~kJ} \mathrm{~mol}^{-1}\right)$ in comparison with the singlet closed-shell structure obtained with the restricted Hartree-Fock (RHF) scheme (134.8 $\left.\mathrm{kJ} \mathrm{mol}^{-1}\right)$, which corresponds to the doubly occupied lowest molecular orbitals. This is a typical structure for the majority of all known diamagnetic molecules in organic chemistry which possess the singlet ground state with the triplet excitation being higher in energy not less than $251.2 \mathrm{~kJ} \mathrm{~mol}^{-1}$ (not less than about $3 \mathrm{eV}$ ) [10-12]. Our PM3 results predict that the studied N-sulfinylanilines are similar to biradicals with close-laying $\mathrm{S}$ and $T$ states [10]. This finding is supported by our UHF calculation of the singlet state (different orbitals for different $\alpha$ and $\beta$ spins). For normal molecules, the UHF calculation of singlet states usually converges to the closed-shell $\mathrm{S}_{0}$ structure (orbitals for $\alpha$ and $\beta$ spins are the same), but for the $p$ - Br-Nsulfinylaniline we have obtained non-zero spin- 
density distribution (Fig. 3,a) and different orbitals for different $\alpha$ and $\beta$ spins. This state with the total spin equal zero (Singlet) exhibits strong spin polarization not only in the benzene ring moiety, but also in the NSO group (Fig. 3,a). Its heat of formation is the lowest $\left(104.92 \mathrm{~kJ} \mathrm{~mol}^{-1}\right)$ among all $\mathrm{S}$ and $\mathrm{T}$ states in the PM3 (UHF and RHF) methods. Comparison with the triplet state spin density (Table 1) indicates that both $\mathrm{S}$ and $\mathrm{T}$ structures correspond to biradical (Fig. 3,b). It is interesting to note that the $\mathrm{T}$ state spin structure is rather similar in the PM3 and DFT methods (Table 1). The main difference concerns only the structure for the singlet openshell state obtained in the framework of PM3 UHF scheme and pure biradical character of the molecule.

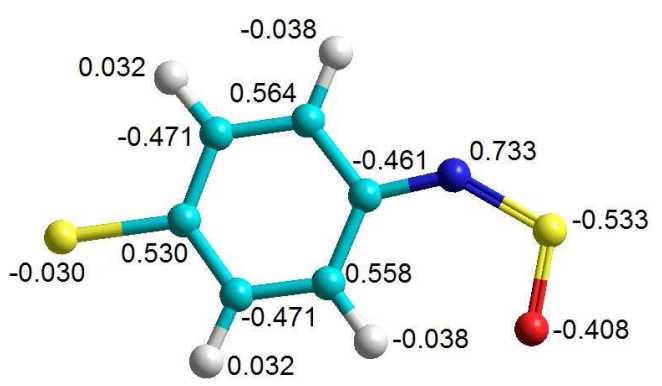

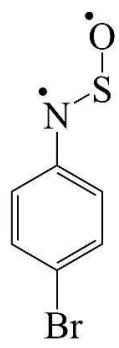

b
Fig. 3. Spin density distribution in the singlet ground state of $p-\mathrm{Br}-\mathrm{N}$-sulfinylaniline calculated by unrestricted Hartree-

Fock (UHF) method in PM3 approximation (a) and the canonical form of this biradical (b)

The spin density in the ring shows strong spin polarization (Fig. 3,a) which is a pure characteristic artifact of the UHF PM3 method [6,8]. However, the spin density distribution indicates the approximate nature of the canonical structure in Fig. 3,b, since the nitrogen and sulfur atoms also bear some large spin population. There are many other peculiarities (especially in benzene ring) determined by the optimized bond lengths and aromaticity indexes which correspond to approximate character of the structure in Fig. 3,b. In fact, this molecule can be presented as a mixture of few canonical structures. Still we can say that this compound is a biradicaloid with certain contribution of the wave function corresponding to canonical form (b).

Experimental X-ray analysis of the crystal structure indicates that the studied N-sulfinylanilines are planar in agreement with DFT calculation for the singlet ground state (Table 1). The out-of-plane distorted triplet state optimized in the UB3LYP DFT method (Table 3) shows the spin density which is similar to those shown in PM3 calculation for both singlet and triplet biradicaloid species (Fig. 3) excepting the strong spin polarization in the ring. One can suspect that the singlet state biradicaloid molecule with the open shell electronic configuration being proper calculated with the MC SCF (or more accurate) method would be higher in energy than the diamagnetic $\mathrm{S}_{0}$ state of the $\mathrm{N}$-sulfinylaniline molecules presented in Table 2. Calculation of the open shell singlet state biradicaloid molecules is a very difficult task in modern quantum chemistry $[10,11]$. The choice of proper DFT functional for such complicated species is still an open question. Thus, we cannot solve this problem in the present work. Nevertheless, for any DFT functional, we can suspect that the N-sulfinylaniline biradicaloid with the singlet open-shell structure would be non-planar species as this is shown here for its triplet state counterpart. The UHF PM3 predictions in terms of heat of formation definitely overestimate the biradicaloid structures by few $\mathrm{kJ} \mathrm{mol}^{-1}$ and the ground state molecule is the closed-shell singlet state for sure (as it is predicted by DFT in agreement with the X-ray analysis for the molecular crystal [2]). However, biradicaloid $\mathrm{S}$ and $\mathrm{T}$ states energies are rather close to the ground state energy level.

The arylsocianate (ArNCO) molecules being much poorer dienophiles in comparison with $\mathrm{N}$-sulfinylanilines indicate the usual diamagnetic behavior as many other organic molecules with the low-lying singlet ground state and the highly excited $\mathrm{T}_{1}$ state. In terms of spin-catalysis concept, the arylsocianates are poor dienophiles in agreement with experiments [2]. The B3LYP optimization shows that these molecules have the closed-shell electronic wave function without any resemblance with the biradicaloid structure.

\section{Conclusions}

Our DFT calculations show for the first time that the N-sulfinylaniline molecules possess the lowlying triplet excited state in the near IR region. They cannot be observed in phosphorescence because of efficient non-radiative quenching induced by the outof-plane NSO vibrations being responsible for internal magnetic interaction that is SOC induced $\mathrm{T}_{1} \rightarrow \mathrm{S}_{0}$ relaxation. We assign the high chemical reactivity of the studied $\mathrm{N}$-sulfinylanilines to efficient probability of the nonadiabatic $S_{0} \rightarrow T_{1}$ quantum transition at a bit higher temperature and moisture above an ambient condition. Orbital symmetry analysis and calculation of spin-orbit coupling matrix element between these states show the driving force for such singlet-triplet transition. The triplet $\mathrm{N}$-sulfinylanilines themselves are unstable species being highly reactive in respect to any environment in a wet air, since they are prone 
to become biradicals with two non-paired electrons. They will be involved into chemical interaction with oxygen, water vapor and other possible molecules of the typical environment, which is otherwise inert at ambient conditions.

In terms of spin-catalysis concept, we have also stressed a high reactivity of the studied N-sulfinylanilines in respect to Diels-Alder cycloaddition with dienes taking into account the relatively low triplet state energy and correlation diagram in Fig. 2. The detailed search of transition states and reaction mechanism of this cycloaddition is under further consideration.

\section{REFERENCES}

1. Kataev E.G., Plemenkov V.V. Interaction of thionyInaphthylamine with cyclopentene // Russ. J. Org. Chem. - 1967. - Vol.4. - P.1094-1096.

2. Synthesis and structure of novel substituted N-sulfinylanilines / Veremeichik Ya.V., Tevs O.A., Krivolapov D.B., Lodochnikova O.A., Plemenkov V.V. // Russ. J. Org. Chem. 2017. - Vol.87. - P.1143-1147.

3. Minaev B., Agren H. Spin uncoupling in molecular hydrogen activation by platinum clusters // J. Mol. Catal. A. 1999. - Vol.149. - P.179-195.

4. Minaev B.F. Spin effects in activation of hydrocarbons: the role of triplet states in catalysis // J. Mol. Catal. A. - 2001. Vol.171. - P.53-72.

5. Gaussian 09, revision C.02 / Frisch M.J., Trucks G.W., Schlegel H.B., et al. - Wallingford: Gaussian, Inc., 2009.

6. Stewart J.J.P. An examination of the nature of localized molecular orbitals and their value in understanding various phenomena that occur in organic chemistry // J. Mol. Model. 2019. - Vol.25. - Article No. 7.

7. Minaev B.F. Spin orientation of the triplet state and new methods in the study of phosphorescence // Phys. Mol. 1979. - Vol.7. - P.34-67.

8. Agren H., Vahtras O., Minaev B. Response theory and calculations of spin-orbit coupling phenomena in molecules // Adv. Quantum Chem. - 1996. - Vol.27. - P.71-162.

9. Ab initio calculations of zero-field splitting parameters in linear polyacenes / Loboda O., Minaev B., Vahtras O., Schimmelpfennig B., Agren H., Ruud K., Jonsson D. // Chem. Phys. - 2003. - Vol.286. - P.127-137.

10. Perumal S., Minaev B., Agren H. Spin-spin and spinorbit interactions in nanographene fragments: A quantum chemistry approach // J. Chem. Phys. - 2012. - Vol.136. P.104702-104718.

11. Baryshnikov G., Minaev B., Agren H. Theory and calculation of the phosphorescence phenomenon // Chem. Rev. - 2017. - Vol.117. - P.6500-6537.
12. Minaev B.F., Kobzev G.I. Response calculations of electronic and vibrational transitions in molecular oxygen induced by interaction with noble gases // Spectrochim. Acta Part A. 2003. - Vol.59. - P.3387-3410.

13. Minaev B. Photochemistry and spectroscopy of singlet oxygen in solvents. Recent advances which support the old theory // Chem. Chem. Technol. - 2016. - Vol.10. - P.519-530.

14. Singlet oxygen photophysics in liquid solvents: converging on a unified picture / Bregnhoj M., Westberg M., Minaev B.F., Ogilby P.R. // Acc. Chem. Res. - 2017. - Vol.50. - P.1920-1927.

15. Minaev B.F., Knuts S., Agren H. On the interpretation of the external heavy-atom effect on singlet-triplet transitions // Chem. Phys. - 1994. - Vol.181. - P.15-28.

Received 14.06.2020

\section{НИЗЬКОЛЕЖАЧИЙ ТРИПЛЕТНИЙ ЗБУДЖЕНИЙ СТАН N-СУЛЬФІНІЛАНІЛІНІВ, ЯК ПОЯСНЕННЯ ЇХ РЕАКЦІЙНОЇ ЗДАТНОСТІ ТА СХИЛЬНОСТІ ДО ЦИКЛО-ПРИЕДНАННЯ В ГРУПІ N-S=O}

\section{Б.П. Мінаєв, В.О. Мінаєва, О.О. Панченко, С.В. Бондарчук}

Розрахунки за теорією функціоналу густини для $n$ - $\mathrm{Br}-$ $\mathrm{N}$-сульфініланіліну та $M$-нітро-N-сульфініланіліну у збудженому синглетному $\left(\mathrm{S}_{0}\right)$ та триплетному $\left(\mathrm{T}_{1}\right)$ станах наведені та проаналізовані з точки зору їх специфічних фізикохімічних властивостей. Так як і інші ароматичні N-сульфініламіни, ці сполуки є досить нестабільними, чутливими до вологого повітря; ми приписуємо цю нестабільність термічно дозволеному збудженню $\mathrm{S}_{0} \rightarrow \mathrm{T}_{1}$, викликаному внутрішніми магнітними силами. Наші розрахунки свідчать про те, що енергетичнащілина $\mathrm{T}_{1}-\mathrm{S}_{0}$ у цих молекулах несподівано низька, а матричний елемент спін-орбітальної взаємодії між цими станами порівняно високий, що допускається правилами відбору симетрії орбіталей. Ми також застосовуємо механізм обміну концепції спін-каталізу, щоб пояснити схильність N-сульфініламінів до цикло-приєднанняДільсаАльдера $з$ дієнами.

Ключові слова: спін-каталіз, цикло-приєднання, сульфініламіни, ТФГ, синглет-триплетна енергетична щілина. 
THE LOW-LYING TRIPLET EXCITED STATE OF

N-SULFINYLANILINES EXPLAINS THEIR REACTIVITY AND INCLINATION TO CYCLOADDITION ACROSS $\mathrm{N}-\mathrm{S}=\mathbf{O}$ GROUP

B.F. Minaev ", V.A. Minaeva, O.O. Panchenko, S.V. Bondarchuk The Bohdan Khmelnytsky National University of Cherkasy, Cherkasy, Ukraine

*e-mail: 392smela2@ukr.net

Density functional theory calculations for $p$ - Br-Nsulfinylaniline and $m$-nitro-N-sulfinylaniline in the ground singlet $\left(\mathrm{S}_{0}\right)$ and triplet $\left(\mathrm{T}_{1}\right)$ excited states are presented and analyzed in terms of their specific physicochemical properties. As all aromatic $\mathrm{N}$-sulfinylamines, these compounds are rather unstable being sensitive to moist air and we assign this instability to the thermally allowed $\mathrm{S}_{0} \rightarrow \mathrm{T}_{1}$ excitation induced by internal magnetic forces. Our calculations indicate that the $\mathrm{T}_{1}-\mathrm{S}_{0}$ energy gap in these molecules is unexpectedly low and spin-orbit coupling matrix element between these states is relatively high, being allowed by the orbital symmetry selection rules. We also apply the exchange mechanism of spin-catalysis concept in order to explain the prone of N-sulfinylamines to the Diels-Alder cycloaddition with dienes.

Keywords: spin-catalysis; cycloaddition; sulfinylamines; DFT; singlet-triplet energy gap.

\section{REFERENCES}

1. Kataev E.G., Plemenkov V.V. Vzaimodeistvie tionilnaftilaminov stsyklopentenom [Interaction of thionylnaphthylamine with cyclopentene]. Russian Journal of Organic Chemistry, 1967, vol. 4, pp. 1094-1096. (in Russian).

2. Veremeichik Ya.V., Tevs O.A., Krivolapov D.B., Lodochnikova O.A., Plemenkov V.V. Synthesis and structure of novel substituted N-sulfinylanilines. Russian Journal of General Chemistry, 2017, vol. 87, pp. 1143-1147.

3. Minaev B., Agren H. Spin uncoupling in molecular hydrogen activation by platinum clusters. Journal of Molecular Catalysis A: Chemical, 1999, vol. 149, pp. 179-195.

4. Minaev B.F. Spin effects in activation of hydrocarbons: the role of triplet states in catalysis. Journal of Molecular Catalysis A: Chemical, 2001, vol. 171, pp. 53-72.

5. Frisch M.J., Trucks G.W., Schlegel H.B.,Scuseria G.E., Robb M.A., Cheeseman J.R., Scalmani G., Barone V., Petersson G.A., Nakatsuji H., Li X., Caricato M., Marenich A., Bloino J., Janesko B.G., Gomperts R., Mennucci B., Hratchian H.P., Ortiz J.V., Izmaylov A.F., Sonnenberg J.L., Williams-Young D., Ding F., Lipparini F., Egidi F., Goings J., Peng B., Petrone A., Henderson T., Ranasinghe D., Zakrzewski V.G., Gao J., Rega N., Zheng G., Liang W., Hada M., Ehara M., Toyota K., Fukuda R., Hasegawa J., Ishida M., Nakajima T., Honda Y., Kitao O., Nakai H., Vreven T., Throssell K., Montgomery Jr.J.A., Peralta J.E., Ogliaro F., Bearpark M., Heyd J.J., Brothers E., Kudin K.N., Staroverov V.N., Keith T., Kobayashi R., Normand J., Raghavachari K., Rendell A., Burant J.C., Iyengar S.S., Tomasi J., Cossi M., Millam J.M., Klene M., Adamo C., Cammi R., Ochterski J.W., Martin R.L., Morokuma K., Farkas O., Foresman J.B., Fox D.J., Gaussian 09, revision C.02. Gaussian, Inc., Wallingford, CT, 2009.
6. Stewart J.J.P. An examination of the nature of localized molecular orbitals and their value in understanding various phenomena that occur in organic chemistry. Journal of Molecular Modeling, 2019, vol. 25, article no. 7.

7. Minaev B.F. Spinovaya orientatsiya tripletnogo sostoyaniya i novye metody $\mathrm{v}$ issledovanii fosforestsentsii [Spin orientation of the triplet state and new methods in the study of phosphorescence]. Physics of Molecules,1979, vol. 7, pp. 34-67. (in Russian).

8. Agren H., Vahtras O., Minaev B. Response theory and calculations of spin-orbit coupling phenomena in molecules. Advances in Quantum Chemistry, 1996, vol. 27, pp. 71-162.

9. Loboda O., Minaev B., Vahtras O., Schimmelpfennig B., Agren H., Ruud K., Jonsson D. Ab initio calculations of zerofield splitting parameters in linear polyacenes. Chemical Physics, 2003, vol. 286, pp. 127-137.

10. Perumal S., Minaev B., Agren H. Spin-spin and spinorbit interactions in nanographene fragments: a quantum chemistry approach. Journal ofChemical Physics, 2012, vol. 136, pp. 104702104718.

11. Baryshnikov G., Minaev B., Agren H. Theory and calculation of the phosphorescence phenomenon. Chemical Reviews, 2017, vol. 117, pp. 6500-6537.

12. Minaev B.F., Kobzev G.I. Response calculations of electronic and vibrational transitions in molecular oxygen induced by interaction with noble gases. Spectrochimica Acta Part A: Molecular and Biomolecular Spectroscopy, 2003, vol. 59, pp. 3387-3410.

13. Minaev B. Photochemistry and spectroscopy of singlet oxygen in solvents. Recent advances which support the old theory. Chemistry and Chemical Technology, 2016, vol. 10, pp. 519-530.

14. Bregnhoj M., Westberg M., Minaev B.F., Ogilby P.R. Singlet oxygen photophysics in liquid solvents: converging on a unified picture. Accounts of Chemical Research, 2017, vol. 50, pp. 1920-1927.

15. Minaev B.F., Knuts S., Agren H. On the interpretation of the external heavy-atom effect on singlet-triplet transitions. Chemical Physics, 1994, vol. 181, pp. 15-28. 